\title{
What do journalists say about covering science during the COVID-19 pandemic?
}

\author{
The pandemic has thrust many mainstream journalists into unfamiliar grounds, including coverage of expert \\ opinion that is not backed up by peer-reviewed content, reporting on preprints, and assessing high-complexity \\ instant-response science. How did they manage? We asked five journalists from mainstream media about \\ their experience.
}

Apoorva Mandavilli is a reporter on science and global health for The New York Times, USA. Chloé Hecketsweiler covers health, pharmacy and biotechnology for Le Monde, France. Rema Nagarajan is a journalist writing about public health for the Times of India, India. Sabine Righetti writes about science and innovation for Folha de S. Paulo, Brazil. Tamar Kahn is a science and health journalist with Business Day, South Africa.

1. We've had an outpour of scientific information during the pandemic. How did you keep up with the volume?

$\mathrm{RN}$ : With a lot of help and not very well. It's almost impossible to read all the stuff that is coming out. So you're dependent upon people who are more qualified to read scientific papers.

SR: A few months ago, a colleague and I found more than ten papers [released] per hour; I'm talking just about scientific papers published in journals at the Web of Science, not preprints or other kinds of scientific information. What I'm trying to do is talk to scientists every single day. I'm asking them which scientific outcome is important, or which one we need to wait to get a better understanding of.

AM: It hasn't been easy. I'm fortunate to work in a newsroom where there are a lot of reporters. And I carved out some specific things I was tracking more closely, like the immunology, for example. I tried narrowing down where I would focus my energies.

$\mathrm{CH}$ : It's not possible to follow everything. But we work as a team. Each of us have a different focus. Twitter is [also] helping us a lot because we follow a lot of key people. We have more filters to choose what's relevant.

TK: It is difficult. One way that I try to filter through the noise is to think about what's of interest to local readers, which means focusing on local clinical trials with vaccines and that kind of thing. I'm on the mailing list for the big research journals, but quite often what happens is, even if something looks interesting, there's another big development here in South Africa, which will push it out of the way, as was

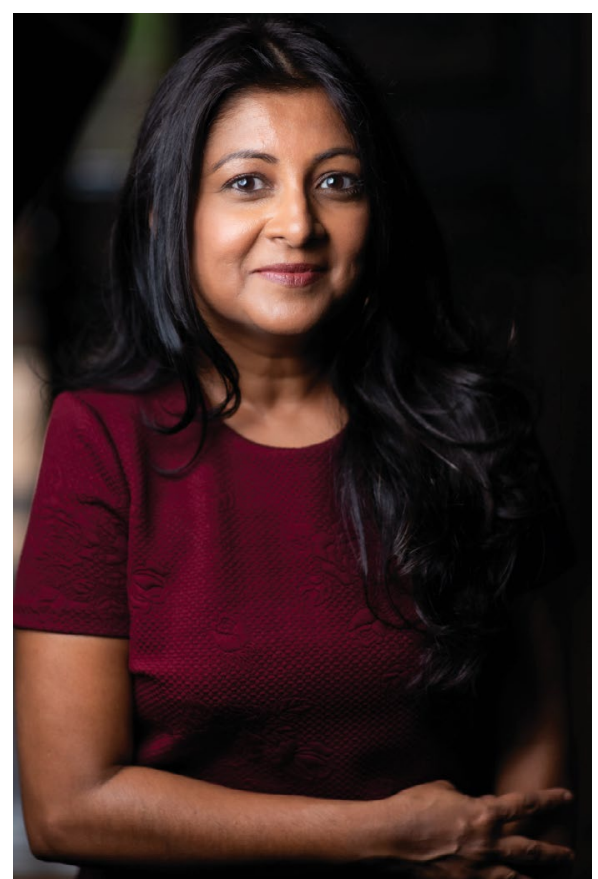

Apoorva Mandavilli

the case with HIV reporting in South Africa in the 2000s.

2. There's also the fast pace of developments. What about balancing the need to inform the public quickly with reporting science accurately?

AM: It was definitely extremely challenging at the beginning. I relied a lot on experts that I trust to tell me 'this is a very big deal' or 'no this is very speculative still'. We all rely on certain journals to be high quality, but during the pandemic even that's been tough; there have been papers in the New England Journal of Medicine and in Lancet that haven't really stood the test of time. So, it's been more complicated. But overall, it's very helpful to have your own sort of peer review happening at the same time.

$\mathrm{CH}$ : We sometimes had this difficult debate on whether we should use, for example, a certain model published through [preprint] platforms, or just wait until it's been peer reviewed. But maybe in the meantime, competitors might have jumped on the information, and we are the only [outlet] not to use it. So it's a difficult balance.

SR: Everybody is very anxious at their homes waiting for an answer or a signal that there is a drug or a vaccine just around the corner. We need to be honest with the readers. I'm always writing lines such as "this is the first step that can lead us to a drug" or "despite the results in cells [that] are very exciting less than $10 \%$ of the drugs that work on cells also work on humans". We have to make sure we are not giving false expectations to the public.

TK: I'm comfortable talking to scientists about some of the uncertainties around the things we are discussing and learning around COVID. In some ways that's no different to any other reporting. [But] there's no question it's much more intense. I have never worked this kind of pace for so long in my career as a journalist.

$\mathrm{RN}$ : There is the push from editors. If a paper comes out [on a high-profile issue], they want it to be reported on. Take for example plasma therapy. Even before any proper study was done, we had a lot of [state] governments here pushing for [it]. There was massive publicity and the health minister spoke about it, which meant that the public thought this is a miracle cure. So those are really difficult [cases] to deal with because the moment some study comes out saying plasma is good, even if the study is pretty weak, the editors get very excited. It becomes really difficult to tell them you can't overhype the study, because that would be a disservice to our readers, giving them false hope. They will tell you yes course, you must put in all the caveats. Now, the copy is in your control, but the placement of the news is not. So if the story goes on the front page, for example, it's already overhyped. Even if you say that I have put caveats in the copy, you're already influencing a lot of your readers. 


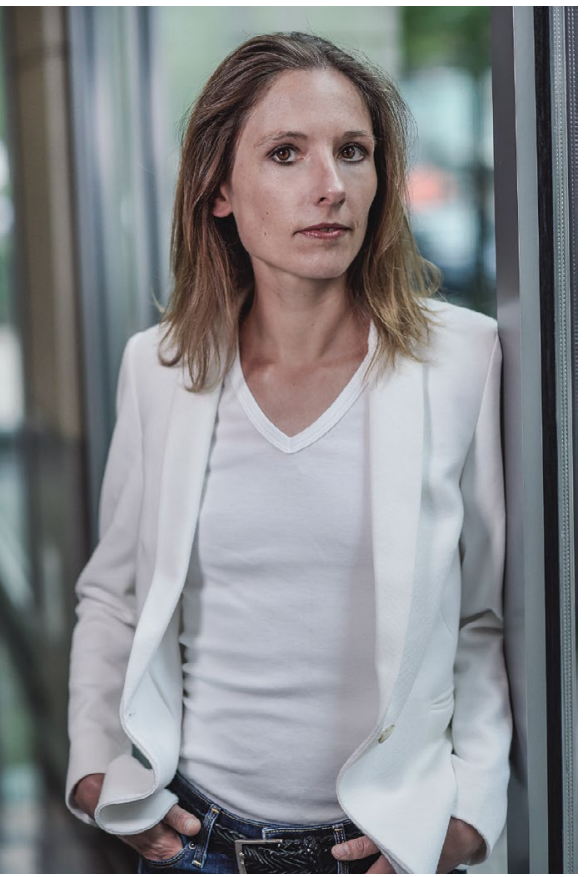

Chloé Hecketsweiler

3. What about handling conflicting reports and the uncertainty surrounding the virus?

AM: As a science writer you learn to become very wary of any scientist who says they have all the answers, especially in a situation like this. So, my go-to sources are all people who are not just good at knowing what they know, but also very honest and candid and careful about saying what they don't know-what the field as a whole doesn't know.

$\mathrm{CH}$ : This was really a challenge. At Le Monde we have a network of very reliable scientists. What was more difficult is that it took a while before we understood that some experts who on paper were very reliable, neutral voices, were in fact not so neutral and had in mind something else-a specific interest or political beliefs influencing what they're saying. Some doctors, for instance, have different opinions about the strategy to deal with COVID; or we had this huge controversy about hydroxychloroquine in France.

$\mathrm{RN}$ : A lot of measures adopted by government were so that people feel good [that something is being done]. A very good example is spraying people with disinfectants. We had scientists creating disinfection tunnels to enter a hospital, saying that, if you spray that will help to disinfect the person, when actually you're carrying COVID inside you. So, it doesn't make much sense to be doing that.
But that's something that governments like to do. It may not be based on science, but they understand the importance of making people believe that something has been done. The way the pandemic is handled is as much about politics as it is about science. You can't combat something only with science.

4. We've also seen cases of rogue scientists giving opinions before questions are settled by evidence, or government directives that don't quite line up with scientific advice. How did you deal with that?

AM: It's really useful, at a time like this, to be skeptical of everything and everybody and to really examine every statement. It's really about looking at the bulk of opinions and not about any one person. Also it's important to ask the right kind of experts. One thing I saw a lot, especially in the early days when we were all desperate for sources, is that some articles were quoting people who had absolutely no expertise to talk about the [appropriate speciality].

$\mathrm{CH}$ : My colleagues covered the controversy about Professor [Didier] Raoult and hydroxychloroquine. We had a lot of discussion about the level of coverage we should have. From a scientific point of view, you have most experts saying, well, what he says is a proof of efficacy for this treatment is not proof, we still need more studies, and we have to be very cautious with these treatments. [But] this professor has been very skilled in talking about how the [pandemic] crisis was managed; it's been a huge buzz in France. It was very difficult for us not to treat that issue [as news], even though from a purely scientific point of view it was not worthy of this level of coverage.

SR: I always try to understand the scientific consensus on a specific area regardless of the opinion of one scientist or the government. The Ministry of Health here in Brazil decided in May to officially include chloroquine in the treatment of COVID-19, without any scientific evidence that it works. Or, president Jair Bolsonaro has stated that he would not get sick from COVID-19 because he was once an athlete, that the virus is a "simple flu", that it does not necessarily have to do social isolation and so on. We need to verify the scientific consensus of practically all declarations.

TK: One of the conversations in the newsroom has been, what exactly is the advice being given by the scientists to the government and how do we break through the opacity that surrounds the government's decision-making processes? Because it has been pretty opaque. Obviously, any government does need to

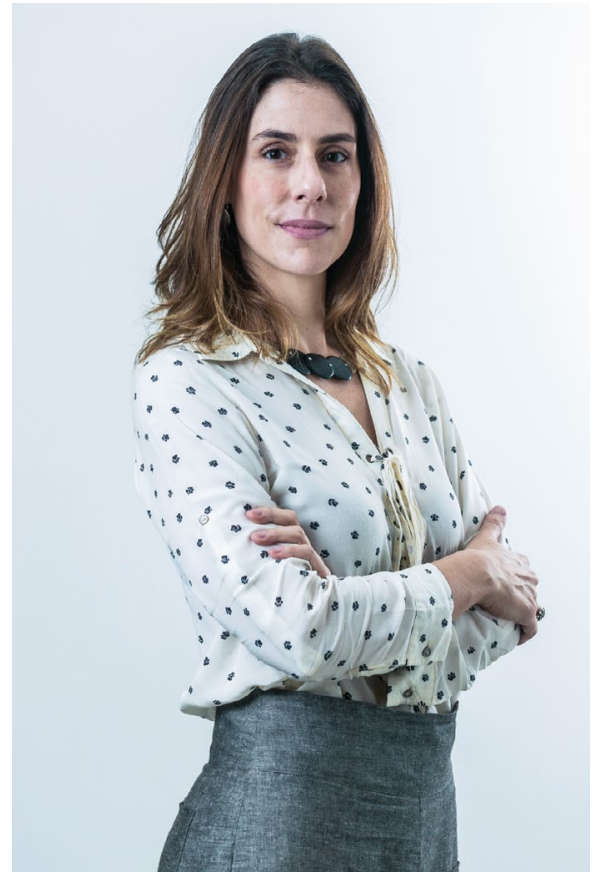

Sabine Righetti

weigh up competing priorities. But the way [the South African government] has talked about science often has a tone that 'oh of course we listen to the scientists', and then advisories reveal there were times when they didn't, and other interest groups were paramount. So there's a healthy skepticism in my newsroom.

$\mathrm{RN}$ : We have the Indian Council for medical research, which is the premier body for scientific research in India. The person who heads that body was part of regular government briefings. But many of the things which they said didn't tally with what is real. I think it was just last month when India finally admitted that we have community transmission. So there is complete denial sometimes, and I think the newspapers play it a little too safe. You don't say 'lies'; you might say 'a misleading statement'. Legacy media like newspapers and television, they are far more hesitant [than digital media] about taking an all-out negative stance against what the government might be saying.

\section{What about preprints-have you had to adapt your reporting to cover these papers, and do you expect preprint coverage to continue beyond the pandemic?}

AM: It was definitely different to be looking at preprints. Because preprints haven't been through peer review they require an even higher bar. That was not really possible early on because everything was a preprint and journals just could not keep up. 
But now that things have slowed down a little bit, I'm being much more selective about which preprints I cover. I usually only cover preprints from groups that have a really good reputation for good work. And work that I think is incredibly interesting or important in some way.

[Preprint coverage] was increasing even before, it's just that the pandemic has really accelerated the pace and visibility of preprints. Biologists in particular have become a lot more comfortable publishing preprints [since the pandemic started]. That trend will probably continue and I don't think it's entirely a bad thing. It's almost like peer review in real time.

$\mathrm{CH}$ : The rule in our paper is to use only science that has been peer reviewed. So, using preprints was very new. But when things slowed down, we changed our approach and used less and less of the preprints. Also, for some of the preprints, afterwards we checked [the published version to see] whether there was a significant difference. And, at least in one occasion we [reported on this].

I think we'll continue using them because things are going so fast. We are always very cautious about preprints that come from unvalidated sources or people we don't know. Because obviously, we have fewer tools to evaluate the quality of the work.

SR: I have never reported a preprint on the pandemic. If I did so I would be even more careful to make it clear that that result can be contested, how it fits with the science in that area and so on. Some journalists have done this very well. But most journalists covering the pandemic in Brazil have no scientific background so it's tricky.

TK: To be honest pre-COVID I was barely aware that was even a thing. It's shot across my radar since COVID. I don't go through them-I don't have the time or the resources to do so. I cover a lot of other things in addition to science, about government health policy and the politics around health. I tend to go looking for them to check the source [for a statement].

$\mathrm{RN}$ : I don't have that kind of pressure to report on preprints. Preprints used to come out [and] you would still have the time to actually talk to other people to ask them whether this is valid. You could still decide whether you wanted to report it. I don't know if that exists anymore, in the sense that there is so much urgency.

6. A few reports are suggesting a bias toward interviewing men in pandemic coverage. Do you agree? What do you think is behind that?

AM: I think that's a combination of factors. There are men who are able to talk a little

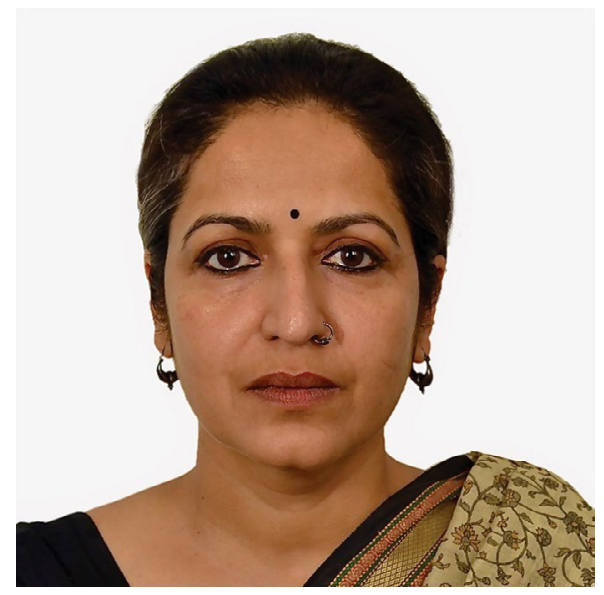

Rema Nagarajan

bit more easily to journalists because they have partners who are taking care of the kids. Also there is an old boys network: men do tend to recommend other men and are more comfortable promoting themselves. So you see their name more often. And there's recall bias. When you're on deadline you're trying to quickly think of people, you may just think of the people whose names have been out there.

Finally, there's also the aspect of women not wanting to be out there as much because there are bigger penalties. If they make mistakes, if they misspeak or are critical of somebody else in the field, that can have much bigger repercussions for them than for white male scientists.

$\mathrm{CH}$ : We have definitely interviewed much more men than women during his epidemic. We have a lot of men in the field of infectious disease. But this is not the only reason. From my experience, women are less available than men. They feel they don't have the time or that what they would say won't be relevant. Men are more willing to put themselves forward even when sometimes they're not the most expert in the field. We realized that quite early, maybe in April or early May, and our chief editor sent an email to all the journalists at Le Monde saying we really need to make more effort to interview more women. I'm not sure that it worked a lot. Even if I tried, I still have more men than women in my daily work.

SR: Yes! This phenomenon is not an exclusivity of the pandemic, but it got worse because of it. Female scientists in Brazil aremuch more reluctant to talk to journalists. Many end up appointing a department head (male) or an adviser (also male) to talk about their own work.

TK: It's true that more men are quoted/interviewed than women, but that isn't unique to COVID-19. Reporters tend to go for the most senior person for comment, and often institutions direct us to them. It takes time and effort to consciously seek out new voices. I do that when I have time, but more often than not, I am working on very tight deadlines and the people who end up being quoted are simply a function of who is willing and able to comment at short notice.

RN: I think $80 \%$ of people who cover health are women. They are very aware of the gender skew in experts.

\section{What do you wish scientists knew} about journalism that could have made the working relationship better during the crisis?

AM: Some scientists make the mistake of thinking that journalists are their partners in getting information about science out there, and that's a misunderstanding. Scientists and journalists can work together in some sense, but journalists are not scientists' friends, nor their partners. We're actually there to [also] hold them accountable. And it would be really helpful if scientists could learn to figure out what is interesting to their colleagues and what is actually useful for a reader to know. Those are sometimes not the same thing.

$\mathrm{CH}$ : What scientists sometimes have a hard time understanding is that we write for a very large audience. Among our readers of course we have scientists who can understand details. But most come from a 'naïve' background. And we have to translate the scientific language. We have to make sure people really understand the point. This is something some scientists do very well, [but] some of them are very reluctant.

SR: Anything would help! In Brazil, scientists are not familiar with the press, they do not have training [or] institutional support to dedicate time to journalists. So journalists struggle to understand findings and talk to scientists. I would very much like scientists to understand that journalists need to write quickly on several different subjects per day, in a clear way for a large lay audience.

TK: For scientists who don't have a prior working relationship with journalists, it's very difficult territory. They are incredibly stretched and really scared about being misquoted or misunderstood. Some of [the fear] is justified, but it can also be difficult to not have that access and not be able to just talk to somebody. It's very difficult to have a real to and fro in a press conference on Zoom. But those conversations, which may be longer, help me as a journalist understand more about the subject. 
RN: I've heard a few experts complain about the fact that journalists call at the last moment and expect them to drop everything and speak to them. Many of the journalists are daily reporters. So they will call up in the evening because the story breaks out maybe sometime in the afternoon, and then you need to catch an expert to comment on it. I don't know whether too many [experts] understand that it's not because journalists are being arrogant, but it's just the way the news cycle flows. That's a sore point always, but in COVID it became more focused.

And there aren't that many well-known experts willing to talk because they're scared of their career prospects, that if they criticize the government maybe they won't be added to the next committee the government forms.

We had two retired scientists who are quoted by everybody. They have nothing to lose. But then that means you're hearing the same people over and over and over again.

\section{Is there another challenge in} covering COVID-19 that we haven't talked about enough?

AM: All of the disinformation has been crazy, and just really exhausting to try and counter. It's also been really difficult to report on topics that are causing people to be very emotional, angry, upset, and depressed. This is a pandemic that has put people very much on edge, and so it's been extremely difficult to report on things that really push people's emotional buttons.

$\mathrm{CH}$ : The biggest challenge was the distance. During the lockdown, it was very difficult to get access to any place; for example, hospitals or scientific institutions. Using only the phone or video conferences is very unusual for journalists. It's the first time

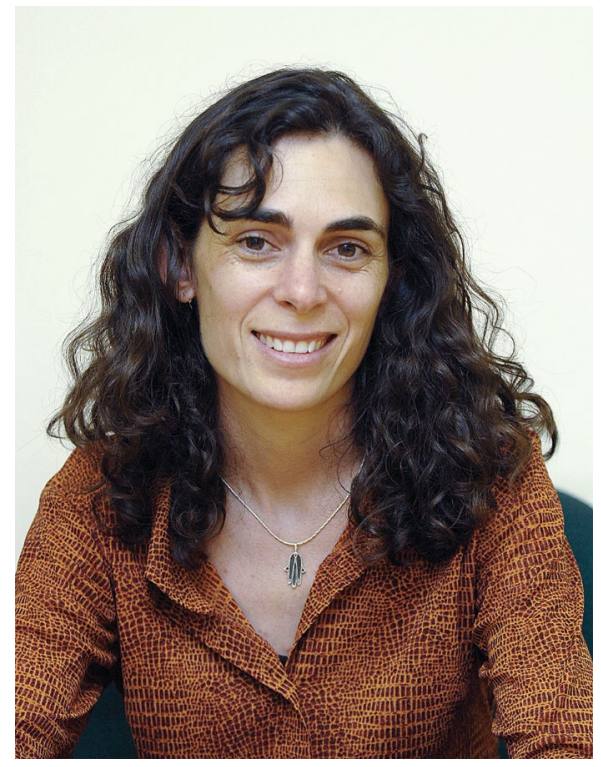

Tamar Kahn

in my life that I have to deal with so many people that I never see. Even for interviews that are straightforward, it's always interesting to go in the lab, the workplace or the hospital, just to see what's going on around the person you're interviewing, and to have a better understanding of the situation. We don't get the same information when we're behind our desk in front of a computer.

SR: The huge challenge for us is verifying the scientific basis of all statements of government. I've been writing pieces about science for the last two decades and I never ever imagined that I would need to check and contest official information! A few days ago, the Science Minister announced that an antiparasitic (nitazoxanide) may slash COVID-19 viral load by $95 \%$. Together with the president, they said nitazoxanide "scientifically reduced viral load". There was no scientific evidence for that. It's hard to write a piece saying official information that comes from a Science Minister and from the president had no scientific evidence. Well we are doing this every single day.

TK: The big elephant in the room for all reporters and not just science reporters is mental health. It's busy and it's intense, and it's been going on for months. It's not acknowledged enough that many journalists are really taking strain. It's not the kind of thing where you go and report on something traumatic and then you go back to your ordinary life, because we are living while we are reporting.

$\mathrm{RN}$ : A large part of our reporting was not just about the science, but on the impact on people. Reporting of people seeking health care. Maybe it's not so much of a problem in countries with a robust health system, but in a country like India, the challenges were huge. Reporting on that was quite a problem because we also faced a government which did not want to admit that there are people not getting [hospital] beds, who can't afford treatment, who are dying because there aren't enough ambulances to take them to the hospital, and things like that. Those logistics, and the actual impact on people who needed care, is a large part [of the reporting] which is beyond science.

\section{Interviewed by Anita Makri}

Published online: 13 January 2021 https://doi.org/10.1038/s41591-020-01207-3 